\title{
ANÁLISE DO CONFLITO DO USO E OCUPAÇÃO DA TERRA EM ÁREA DE PRESERVAÇÃO PERMANENTE ATRAVÉS DO SIG.
}

Aline Kuramoto Gonçalves ${ }^{1}$

Zacarias Xavier de Barros ${ }^{2}$

Ronaldo Alberto Pollo ${ }^{3}$

\begin{abstract}
RESUMO
Este trabalho teve como objetivo mapear as classes de uso e ocupação do solo e seus respectivos conflitos nas Áreas de Preservação Permanente (APPs) na bacia hidrográfica do Ribeirão São Pedro Botucatu (SP) com a utilização de técnicas de sensoriamento remoto - obtido por imagem de satélite de 2011 - e do uso de geoprocessamento. Para tanto, utilizou-se de técnicas de geoprocessamento, sendo a integração de informações realizada no Sistema de Informações Geográficas (SIG) - IDRISI, aliada ao uso de cartas digitais, editada pelo Instituto Brasileiro de Geografia e Estatística - IBGE, escala 1:50.000e imagens de satélite LANDSAT - 5 (2011) sensor TM (Thematic Mapper) com resolução espacial de $30 \times 30$ metros, cedidas pelo Instituto Nacional de Pesquisas Espaciais (INPE).O Sistema de Informações Geográficas (SIG) utilizado foi o IDRISI Selva e o software, CartaLinx. A realização deste trabalho teve como suporte legal a legislação ambiental, mais especificamente, a Lei Federal $n^{\circ} 12.651 / 12$. Desta forma, o estudo de da bacia hidrográfica torna-se uma ferramenta importante para entender sua dinâmica em relação ao uso e ocupação de sua área e caracterizar os seus problemas ambientais e tendo como suporte legal para a preservação e conservação das terras a legislação ambiental.
\end{abstract}

PALAVRAS-CHAVE: Bacia Hidrográfica, Legislação Ambiental, Geoprocessamento.

\section{CONFLICT ANALYSIS OF THE USE OF LAND OCCUPATION IN AREAS PERMANENT PRESERVATION THROUGH GIS.}

\footnotetext{
${ }_{1}^{1}$ Geógrafa, Mestranda em Agronomia, UNESP/FCA. aline587@gmail.com

2 Eng ${ }^{\circ}$ Agrônomo, Professor do Depto. de Eng. Rural, UNESP/FCA, Botucatu - SP.zacariasxb@fca.unesp.br

${ }^{3}$ Geógrafo, Doutorando em Agronomia, UNESP/FCA, rapollo@fca.unesp.br
} 


\begin{abstract}
This study aimed to map the classes of use and occupation and their conflicts in Areas of Permanent Preservation (APPs) in the basin of Ribeirão São Pedro - Botucatu (SP) with the use of remote sensing techniques - image obtained by satellite 2011 - and the use of GIS. For this, we used the GIS techniques, and the integration of information held in the Geographic Information System (GIS) - IDRISI, coupled with the use of digital maps, published by the Brazilian Institute of Geography and Statistics IBGE, scale 1: 50,000 and satellite images LANDSAT - 5 (2011) sensor TM (Thematic Mapper) with spatial resolution of $30 \times 30$ meters, provided by the National Institute for Space Research (INPE).The Geographic Information System (GIS) was used IDRISI Selva and software, CartaLinx. This work had as legal support environmental legislation, specifically, the Federal Law 12.651 / 12. Thus, the study of the watershed becomes an important tool to understand its dynamics in relation to the use and occupation of their area and to characterize their environmental problems and taking as legal counsel to the preservation and conservation of the land to support environmental legislation.
\end{abstract}

KEY-WORDS: Watershed, Environmental Legislation, GIS.

\title{
EL ANÁLISIS DEL CONFLICTO DE LA UTILIZACIÓN DE LA OCUPACIÓN DEL SUELO EN ÁREAS DE PRESERVACIÓN PERMANENTE A TRAVÉS DE LO SIG.
}

\begin{abstract}
RESUMEN
Este estudio tuvo como objetivo mapear las clases de uso y la ocupación y sus conflictos en Áreas de Preservación Permanente (APPs) en la cuenca de Ribeirão São Pedro - Botucatu (SP) con el uso de técnicas de teledetección - imagen obtenida por satélite de 2011 - y la uso de los SIG. Para ello, hemos utilizado las técnicas de SIG, y la integración de la información contenida en el Sistema de Información Geográfica (GIS) - IDRISI, junto con el uso de mapas digitales, publicado por el Instituto Brasileño de Geografía y Estadística - IBGE, a escala 1: 50.000 y las imágenes de satélite LANDSAT - 5 (2011) TM sensor (Thematic Mapper) con una resolución espacial de 30 × 30 metros, proporcionada por el Instituto Nacional de Investigación (INPE) .El sistema de Información Geográfica del Espacio (SIG) se utilizó IDRISI Selva y el software, CartaLinx. Este trabajo contó con el apoyo legislación legal ambiental, específicamente, la Ley Federal $N^{\circ}$ 12651/12. Por lo tanto, el estudio de la cuenca passe una herramienta importante para entender su dinámica en relación con el uso y la ocupación de su área y para caracterizar sus problemas ambientales y tomar el Asesor Jurídico de la preservación y conservación de la tierra para apoyar la legislación medioambiental.
\end{abstract}

PALABRAS-CLAVE Cuenca, Legislación Ambiental, SIG.

\section{INTRODUÇÃO}

Ao se apropriar do espaço e dos recursos naturais, a ação humana transforma rapidamente a paisagem natural com muito mais intensidade que a ação da natureza, e gerando impactos no ambiente (ROSS, 2009). Esses impactos podem atingir diferentes proporções de acordo com a característica do meio.

Assim, para barrar ou minimizar a intensidade das ações antrópicas que desencadeiam as degradações do meio ambiente existem as leis ambientais 
brasileiras, tendo a sua importância para a preservação do meio ambiente, assim exercendo menor impacto direto e qualidade de vida aos seres vivos.

O Código Florestal (Lei 12.651/12) que se destaca como um método de gestão ambiental através da preservação do meio ambiente e dos recursos naturais através de duas principais fontes de proteção ambiental - previstas através de situações de preservação e conservação - que são as Áreas de Preservação Permanente (APP) e as áreas de Reserva Legal $(R L)$. No seu ordenamento jurídico brasileiro têm a sua importância quanto à proteção das florestas, ao uso sustentável dos recursos naturais e das demais formas de vegetação.

Durante toda a sua vigência ao longo dos anos, o Código Florestal Brasileiro sofreu várias alterações em seu conteúdo, de forma que garantisse a qualidade de vida a todos os brasileiros através da preservação e conservação dos recursos naturais.

Dessa forma, este trabalho teve como objetivo gerar um mapa de conflito do uso e ocupação em Área de Preservação Permanente da bacia hidrográfica do Ribeirão São Pedro, contendo a delimitação das APPs previstas na legislação ambiental brasileira.

Contudo, foram utilizadas técnicas de Geoprocessamento e Sensoriamento Remoto que constituem hoje, um importante conjunto de ferramentas aplicáveis ao planejamento geográfico para a obtenção de dados a serem utilizados no planejamento ambiental na bacia hidrográfica, tanto em níveis regionais quanto municipais. Assim observa-se o desenvolvimento marcante das geotecnologias (Sensoriamento Remoto e Geoprocessamento) que disponibilizam uma série de ferramentas que auxiliam na investigação da adequação do uso do solo em Áreas de Preservação Permanente (AULICINO et al., 2000; COSTA et al., 1996).

\section{DESENVOLVIMENTO}

As Áreas de Preservação Permanente (APPs) foram criadas para proteger o ambiente natural, o que significa de acordo com Zanatta (2010) "não são áreas apropriadas para alterações de uso da terra. Assim, essas áreas devem ser cobertas 
com a vegetação original". Dessa maneira, minimizar os impactos antrópicos que aceleram processos naturais erosivos do solo e assim contribuindo para a regularização do fluxo hídrico nos cursos d'água e a conservação da flora e fauna.

A Lei $n^{\circ} 12.651$ (17 de outubro de 2012), em seu Art. $4^{\circ}$ estabelece que:

Art. $4^{\circ}$. Considera-se Área de Preservação Permanente, em zonas rurais ou urbanas, para os efeitos desta Lei:

I - as faixas marginais de qualquer curso d'água natural, desde a borda da calha do leito regular, em largura mínima de:

a) 30 (trinta) metros, para os cursos d'água de menos de 10 (dez) metros de largura;

b) 50 (cinquenta) metros, para os cursos d'água que tenham de 10 (dez) a 50 (cinquenta) metros de largura;

c) 100 (cem) metros, para os cursos d'água que tenham de 50 (cinquenta) a 200 (duzentos) metros de largura;

d) 200 (duzentos) metros, para os cursos d'água que tenham de 200 (duzentos) a 600 (seiscentos) metros de largura;

e) 500 (quinhentos) metros, para os cursos d'água que tenham largura superior a 600 (seiscentos) metros; [...]. (BRASIL, CÓDIGO FLORESTAL, Lei $n^{\circ}$. 12.727).

Para exemplificar o Código Florestal fez-se uma tabela síntese (Tabela 1) com a metragem em relação à faixa de preservação permanente de acordo com a largura do curso d'água.

Tabela 1 - Metragem das Áreas de Preservação Permanente

\begin{tabular}{c|c} 
Largura (Rios ou Córregos) & Faixa de Preservação \\
\hline Até 10 metros & $30 \mathrm{~m}$ em cada margem \\
\hline Entre 10 e 50 metros & $50 \mathrm{~m}$ em cada margem \\
\hline Entre 50 e 200 metros & $100 \mathrm{~m}$ em cada margem \\
\hline Entre 200 e 600 metros & $200 \mathrm{~m}$ em cada margem \\
\hline Superior a 600 metros & $500 \mathrm{~m}$ de cada margem \\
\hline Nascentes & $50 \mathrm{~m}$ no entorno da nascente
\end{tabular}

Fonte: BRASIL (2012)

Outro fator importante, de acordo com a Tabela 1 consiste nas obrigações determinadas dentro da lei quanto à proteção e preservação das Áreas de Preservação Permanente e a manutenção da Reserva Legal, na qual se constitui de 
uma parcela de vegetação nativa em propriedades rurais, têm se destacado nas discussões de estratégia para o uso sustentado das propriedades.

No Brasil a bacia hidrográfica é unidade territorial para implementação de diversas políticas atuais sob o que decorre da proteção e conservação dos recursos hídricos, no que tange a Política Nacional de Recursos Hídricos e a atuação do Sistema Nacional de Recursos Hídricos.

A gestão local da bacia hidrográfica demanda a observação de certas características ambientais, sociais e econômicas e deve-se adorar a esse sistema, pois, compreende a sua área geográfica formada por cursos d'água e seus afluentes, direciona a ocupação humana que se abastece de suas águas, mas para monitorar "a qualidade da água de um manancial depende, portanto, dos usos e atividades desenvolvidas em toda a bacia hidrográfica" (MOTTA, 1995, p. 107).

Dessa forma, o uso da unidade territorial a bacia hidrográfica deverá ter como propósito fundamental articular a organização espacial e ambiental, para que possa estar em equilíbrio no ambiente, bem como priorizar a racionalidade e a estabilidade dos aspectos do espaço natural e das paisagens de diferentes áreas.

A bacia hidrográfica do Ribeirão São Pedro, situada no município de Botucatu, possui uma área de 1393,84 ha. Sua situação geográfica é definida pelas coordenadas: Latitude $22^{\circ} 52^{\prime} 31^{\prime \prime}$ a $22^{\circ} 56^{\prime} 17^{\prime \prime}$ S e Longitudes $48^{\circ} 21^{\prime} 02^{\prime \prime}$ a $48^{\circ} 23^{\prime}$ 28" WGr (Figura 1). 


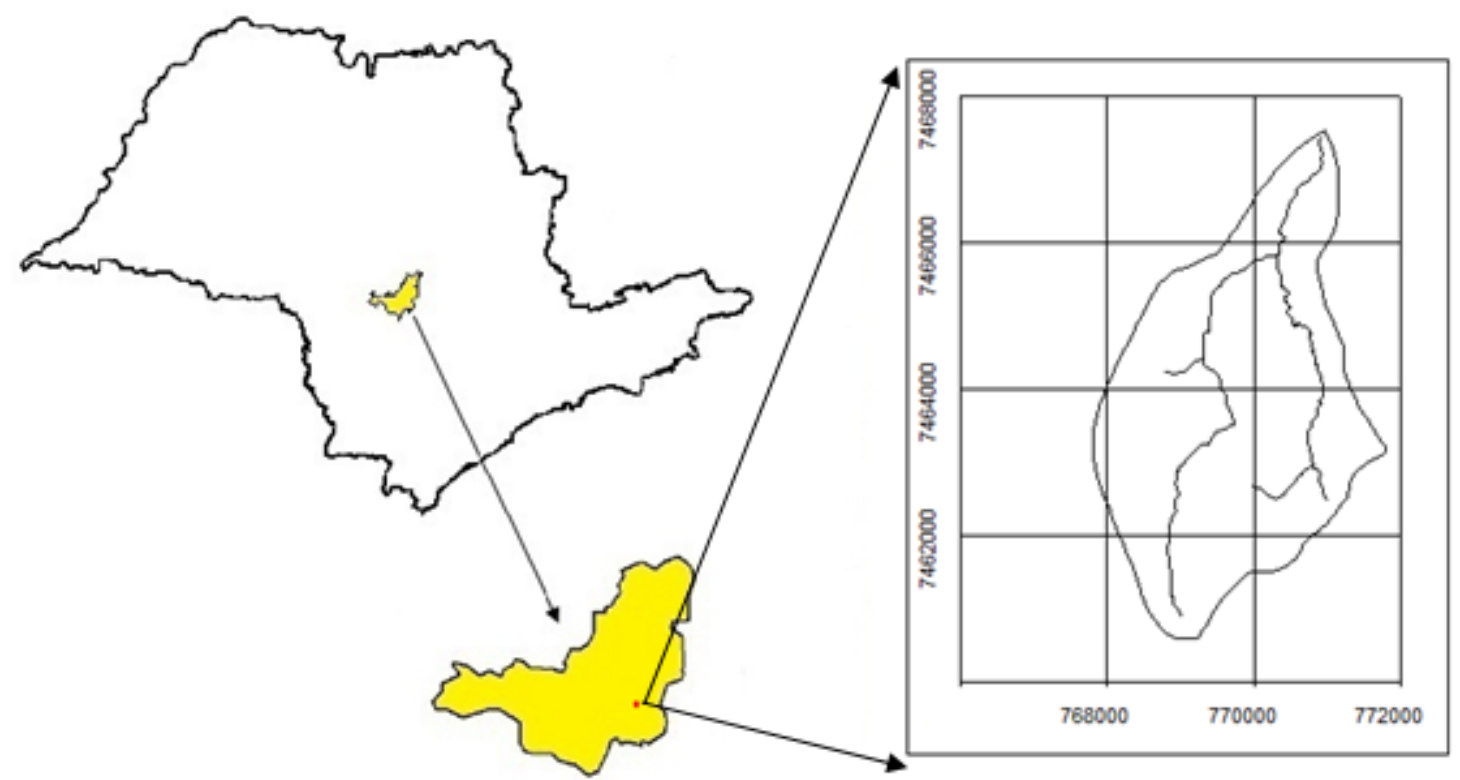

Figura 1 - Localização da microbacia do Ribeirão São Pedro no estado de São Paulo

O clima predominante do município, classificado segundo o sistem Köppen é do tipo Cwa - Clima Mesotérmico de Inverno Seco - em que a temperatura do mês mais frio é inferior a $18^{\circ} \mathrm{C}$ e do mês mais quente ultrapassa os $22^{\circ} \mathrm{C}$.

Segundo Piroli (2002), os solos ocorrentes na área foram classificados como: Latossolos Vermelho-Amarelos Distróficos (LVAd1), Neossolos Litólicos Eutróficos (RLe), Latossolos Vermelhos Distróficos (LVd) e Neossolos Litólicos Eutróficos (RQotípico).

Os pontos de controle (coordenadas) para o georreferenciamento e os pontos de máxima altitude para digitalização do limite da microbacia tiveram como base a Carta Planialtimétrica em formato digital, editada pelo Instituto Brasileiro de Geografia e Estatística - IBGE (1973), folha de Botucatu (SF-22-R-IV-3), em escala 1:50000. Utilizou-se a imagem de satélite digital, bandas 3, 4 e 5 do sensor "Thematic Mapper" do LANDSAT - 5, da órbita 220 , ponto 76 , quadrante A, passagem de 2011 , escala $1: 50000$.

O Sistema de Informações Geográficas (SIG) utilizado foi o SIG IDRISI Selva para o processamento das informações georreferenciadas, na conversão dos dados 
vetoriais em imagem raster e na elaboração do mapa final do conflito uso e ocupação em APP.

O "software" CartaLinx foi utilizado na digitalização do limite da microbacia, da rede de drenagem e das áreas de cobertura vegetal, obtidas através de fotografias aéreas

Assim, a bacia hidrográfica do Ribeirão São Pedro apresenta uma área total de 1393,84 hectares e, constatou que as Áreas de Preservação Permanente correspondem a 92,22 hectares. Por meio da interpretação da imagem de satélite digital LANDSAT-5, no ano de 2011, identificou-se quatro (4) classes sendo: mata ciliar, pastagem, reflorestamento e solo exposto, Figura 1.

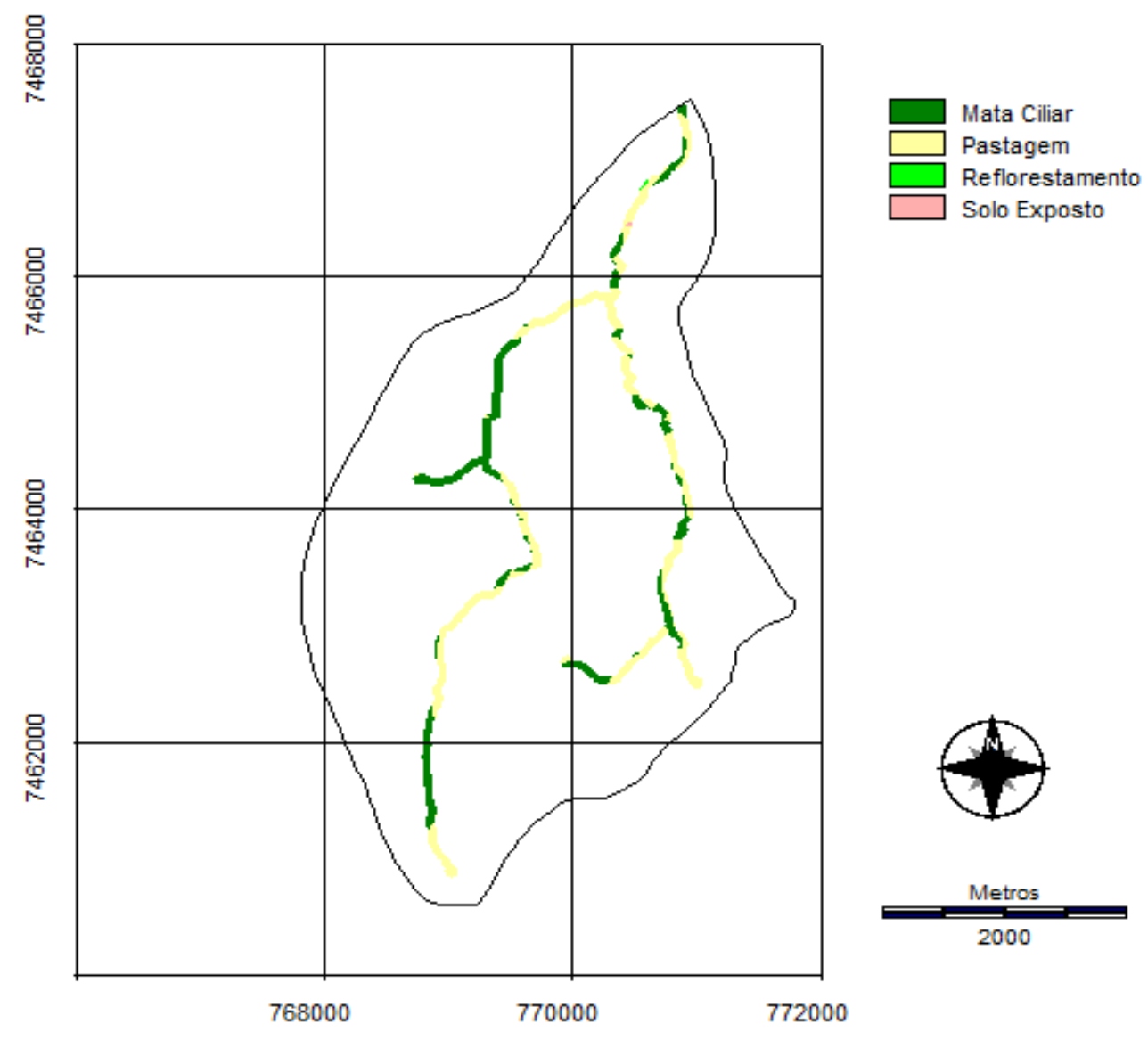

Figura1- Mapa Classes do Conflito Uso e Ocupação em APP na Bacia do Ribeirão São Pedro, no ano de 2011. 
No que compreende as classes de conflitos do uso e ocupação em APP na bacia em estudo, foi possível através do uso do software IDRISI quantificar em hectares, conforme a Tabela 2.

Tabela 2 - Classes do Conflito Uso e Ocupação em APP na Bacia do Ribeirão São Pedro (2011).

\begin{tabular}{ccccc}
\hline Classes de uso da Terra & \multicolumn{2}{c}{ APPs } & \multicolumn{2}{c}{ Conflitos } \\
\hline & (ha) & $\%$ & (ha) & $\%$ \\
Mata Ciliar & 38,59 & 41,84 & - & - \\
Pastagem & 53,25 & 57,74 & 53,25 & 99,29 \\
Reflorestamento & 0,20 & 0,22 & 0,20 & 0,37 \\
Solo Exposto & 0,18 & 0,20 & 0,18 & 0,33 \\
\hline Total & $\mathbf{9 2 , 2 2}$ & $\mathbf{1 0 0}$ & $\mathbf{5 3 , 6 3}$ & $\mathbf{1 0 0}$ \\
\hline
\end{tabular}

Observa-se que no ano de 2011, que na bacia hidrográfica do ribeirão São Pedro a intervenção da atividade da pastagem têm causado impactos ambientais no meio natural com relação a mata ciliar e consequentemente, o descumprimento da legislação ambiental no que se refere a sua proteção e conservação com base no Código Florestal vigente. Da área de APP que corresponde à mata ciliar somente 38,59 hectares estão ainda conservados, no total de 92,22 hectares que deveriam existir.

De maneira geral, a APP por lei deveria ser ocupada pela vegetação nativa, porém está sendo ocupada por outras atividades, deixando assim a sua função ambiental para a manutenção do equilíbrio natural.

A aplicação da tecnologia de Sistemas de Informação Geográfica (SIG) facilita a maneira de como o uso do solo pode ser monitorado, pois técnicas relativamente simples podem fornecer informações que permite a avaliação pontual e temporal, reparação e readequação dos usos, a um custo aceitável. Uma questão importante na adoção das técnicas de SIG para o planejamento do uso do solo é a atividade agrícola (PELEGRIN, 2001). 


\section{CONCLUSÃO}

O presente trabalho pretendeu colaborar para o uso de geotecnologias para o monitoramento da bacia hidrográfica para poder aplicar a legislação ambiental de forma a melhorar o seu estado de degradação ambiental ocasionado pelo uso e ocupação das terras de maneira inadequada.

Assim, foi analisado o conflito do uso da terra na área de APP da bacia, enfatiza-se que esta forma de monitoramento e a facilidade ao acesso a tecnologias de sistemas de informações geográficas tornaram-se importantes meios para os estudos na área ambiental e além da necessidade de estudos para que as situações apresentadas anteriormente sejam alteradas por meio de práticas de preservação e conservação do meio ambiente de maneira a integrar no contexto jurídico

\section{REFERÊNCIAS}

BRASIL. Lei $\mathbf{n}$ o 12.727, de 17 de outubro de 2012. Disponível em<http://www.planalto.gov.br/ccivil_03/_Ato2011-2014/2012/Lei/L12727.htm> Acesso em: 13 nov. 2012.

BRASIL. Lei $\mathbf{n}^{\circ}$. 12.651, de 25 de maio de 2012. Dispõe sobre a proteção da vegetação nativa. 2012. Disponível em: <http://www.planalto.gov.br/ccivil_03/_Ato2011-2014/2012/Lei/L12651.htm>.

CHRISTOFOLETTI, A. Geomorfologia. 2a Edição. São Paulo: Edgard Blücher, 1980.

MOTTA, S. Preservação e conservação de recursos hídricos. 2.ed. Rio de Janeiro: ABES, 1995.

PELEGRIN, L. A. Técnicas de sensoriamento remoto e geoprocessamento aplicadas ao mapeamento do uso do solo: a Bacia do Rio Pará como um exemplo. 2001. 109p.

Dissertação (Mestrado em Analise Espacial) - Pontifícia Universidade Católica de Minas Gerais, Belo Horizonte, MG. 2001

ROSS, Jurandyr Luciano Sanches. Ecogeografia do Brasil: subsídios para planejamento ambiental. São Paulo: Oficina de Textos, 2009.

SANTOS, R.F.dos. Planejamento Ambiental: teoria e prática. São Paulo: Oficina de textos,2004.

ZANATTA, F.A.S. Gestão das águas e planejamento ambiental da bacia hidrográfica do rio Paranapanema: análise da situação ambiental das áreas de preservação permanente ao longo do canal principal no baixo curso do rio Paranapanema.Presidente Prudente: [s,n].2010.121f.Trabalho de conclusão (bacharelado- Geografia)- UNESP/FCT. 